\title{
Review of Economically Important Cattle Tick and Its Control in Ethiopia
}

\author{
Nejash Abdela Ahmed \\ Jimma University College of Agriculture and Veternary Medicine, chool of Veterinary Medicine
}

\begin{abstract}
Ethiopia has the largest livestock population in Africa, but the contribution for the economic aspect of the country is still lowest amount and disease can be considered as major constrain. Ticks are the most important ectoparasites of livestock in tropical and sub-tropical areas. Ethiopia is not exceptional and ticks are responsible for severe economic losses both through the direct effects of blood sucking and indirectly as vectors of pathogens and toxins. Feeding by large numbers of ticks causes reduction in live weight gain and anaemia among domestic animals, while tick bites also reduce the quality of hides. However, the major losses caused by ticks are due to the ability to transmit protozoan, rickettsial and viral diseases of livestock, which are of great economic importance world-wide. This review concerns with general aspects of tick biology, the taxonomy, pathogenic effects and methods for the control of ticks. ticks belong to the suborder Ixodida, which contains a single super family, the Ixodoidea, which is divided into two major families, Argasidae (soft ticks) and Ixodidae (hard ticks), and the rare family Nuttalliellidae, with a single African species. The main tick genera found in domestic animals of Ethiopia are Amblyomma, Hyalomma, Rhipicephalus, Haemaphysalis and Rhipicephalus (Boophilus). Various breeds of cattle differ in their response to tick infestations. Bos indicus pure breeds and crossbreeds were reported to be more innately resistant than Bos Taurus breeds. The conventional method of controlling tick infestations in Ethiopia is application of acaricide, either by hand spraying, by hand dressing. Therefore, to minimize tick adverse effect appropriate and timely strategic control measures are crucial.
\end{abstract}

Keywords: Acaricide, Argasidae, Ectoparasites, Ethiopia, Ixodidae, Ticks,

\section{INTRODUCTION}

Ethiopia is believed to have the largest livestock population in Africa. This livestock sector has been contributing considerable portion to the economy of the country, and still promising to rally round the economic development of the country (CSA, 2013). In Ethiopia, livestock production remains crucial and represents a major asset among resource-poor small holder farmers by providing milk, meat, skin, manure and traction force (Mesfin and Lemma, 2001). The contribution of livestock to the national economy particularly with regard to foreign currency earnings is through exploration of live animal, meat and skin and hides (MoARD, 2008).

Poor health and productivity of animal due to disease has considerably become the major stumbling block to the potential of livestock industry (Mekonnen et al., 2001). Now a day parasitism represents a major obstacle to development and utilization of animal resource. In Ethiopia ectoparasites in ruminant causes serious economic losses to small holder farmers, the tanning industry and country as a while through mortality of animals, decreased production, downgrading and rejection of skin and hide (Tiki and Addis, 2011). From the ectoparasites, ticks are ranked as the most economically important of livestock in tropics including sub-Saharan Africa (Jongejan and Ulienberg, 2004). Ticks are small, wingless ectoparasitic arachinid arthropods that are cosmopolitan and prevalent in warmer climates (Olwoch et al., 2009)

Ticks cause substantial losses in cattle production, in terms of diseases, reduced productivity and fertility and often death, and are economically the most important ecto-parasites of cattle (Rajput et al., 2006). Huruma et al. (2015) indicated that different ticks have different predilection sites on the host's body. Ticks suck blood; damage hides and skins introduce toxins and predispose cattle to myiasis and dermatophilosis (Mtshali et al., 2004 and Marufu, 2008). Furthermore, they reduce body weight gains and milk yield, in addition to creating sites for secondary invasion by pathogenic organisms (Kaufman et al., 2006 and Marufu, 2008). More significantly, ticks transmit diseases from infected cattle to healthy ones. Ticks transmit a greater variety of pathogenic micro-organisms than any other arthropod vector group, and are among the most important vectors of diseases affecting animals (Jongejan and Ulienberg, 2004).

According to Walker et al., 2003 ticks which are considered to be most important to health of domestic animal in Africa comprise about seven genera. Among these genera the main tick genera found in Ethiopia includes Ambylomma, sub genus Rhipicephalus (Boophilus), Haemaphysalis, Hyalomma and Rhipicephalus. The genus Ambylomma and Rhipicephalus are predominating in many parts of country, Hyalomma and sub genus Rhipicephalus (Boophilus) also have significant role (Solomon et al., 2001).

Due to economic and veterinary importance of ticks their control and transmission of tick born diseases remain challenge for the cattle industry of the world and it is a priority for many countries in tropical and subtropical regions (Lodos et al., 2000).. Therefore the objective of this paper is to review available literature on tick biology, the taxonomy, pathogenic effects and methods for the control of ticks and highlighting status of 
ticks and tick borne haemoparasitic diseases in Ethiopia

\section{LITERATURE REVIEW}

\subsection{Classification of ticks}

Ticks are within a member called the phylum (Arthropoda), class (Arachnida), sub class (Acari) and Order (Parasitiformes) (Torr et al., 2003). Within the Parasitiformes, ticks belong to the suborder Ixodida, which contains a single super family, the Ixodoidea, which is divided into two major families, Argasidae (soft ticks) and Ixodidae (hard ticks), and the rare family Nuttalliellidae, with a single African species (Rodriguez-Vivas et al., 2004).

The family Ixodidae, or hard ticks, contains some 683 species. As adults, Ixodids exhibit prominent sexual dimorphism: the scutum covers the entire dorsum in males, but in females (and immatures) the scutum is reduced to a small podonotal shield behind the capitulum, thereby permitting great distention of the idiosomal integument during feeding (Lora, 2001). Ixodidae ticks are relatively large and comprise thirteen genera. Seven of these genera contain species of veterinary and medical importance:Amblyomma, sub genus Rhi.(Boophilus), Rhipicephalus, Haemaphysalis, Hyalomma, Dermacentor and Ixodes (Rodriguez-Vivas et al., 2004).

The family Argasidae, or soft ticks, consists of about 185 species worldwide and have one important genus that infests cattle, Ornithodoros (Latif and Walker, 2004). Adult argasids lack a dorsal sclerotized plate or scutum, their integument is leathery and wrinkled, their mouthparts are not visible from above, and they show no obvious sexual dimorphism. Argasidae are wandering ticks, which only remain on their host while feeding (Lora, 2001 and Barker and Murrell, 2004).

\subsection{Morphology of Ticks}

Tick morphology consists of two primary regions, the mouthparts (capitulum) and the body (idiosoma). The mouthparts on hard ticks protrude in front of the body and are visible from above (Figure 1), but the body of soft ticks extends forward above the mouthparts so they are only visible from beneath. The body of ticks includes the eyes, legs, and respiratory, digestive and reproductive structures.

Ticks are the largest and most conspicuous members of the order acarina; they feed only on the blood of vertebrates, e.g., mammals, birds, reptiles and amphibians (Wall and Shearer, 2001). Ticks differ from other mites; they are larger and have recurved teeth or ridges on the central mouthparts (called the holdfast organ). Ticks do not have wings and they cannot jump and they cannot run, hop, fly or even move quickly. They also have a sensory pit on each of the first pair of legs known as Haller'sorgan which is packed with chemoreceptor setae used in host location. This pit detects stimuli such as heat and carbon dioxide. Ticks also detect light and dark as well as shapes, shadows and vibrations all stimuli that help them find their vertebrate hosts (Latif and Walker, 2004). Ixodidae ticks are relatively large, ranging between 2 and $20 \mathrm{~mm}$ in length. Ixodidae ticks are characterized by the presence of a rigid chitinous scutum that covers the entire dorsal surface of the adult male whereas it extends only for a small area in the female (Barker and Murrell, 2004).

The mouthparts (capitulum) have three specialized structures called palps, chelicerae and a hypostome that are attached to a base called the basis capituli (Houseman, 2013) The body (idiosoma) of ticks is typically not hardened to a great extent. In hard ticks, most of the exterior cuticle is soft and has many internal folds that look like grooves on the surface of the body. The uniform, rectangular folds located on the rounded posterior end of hard ticks are called festoons (Figure 1). Unfolding and stretching of the soft cuticle along these grooves allows immature and adult female hard ticks to take enormous blood meals and swell to weigh 50 to 100 times their original weight (Houseman, 2013) 

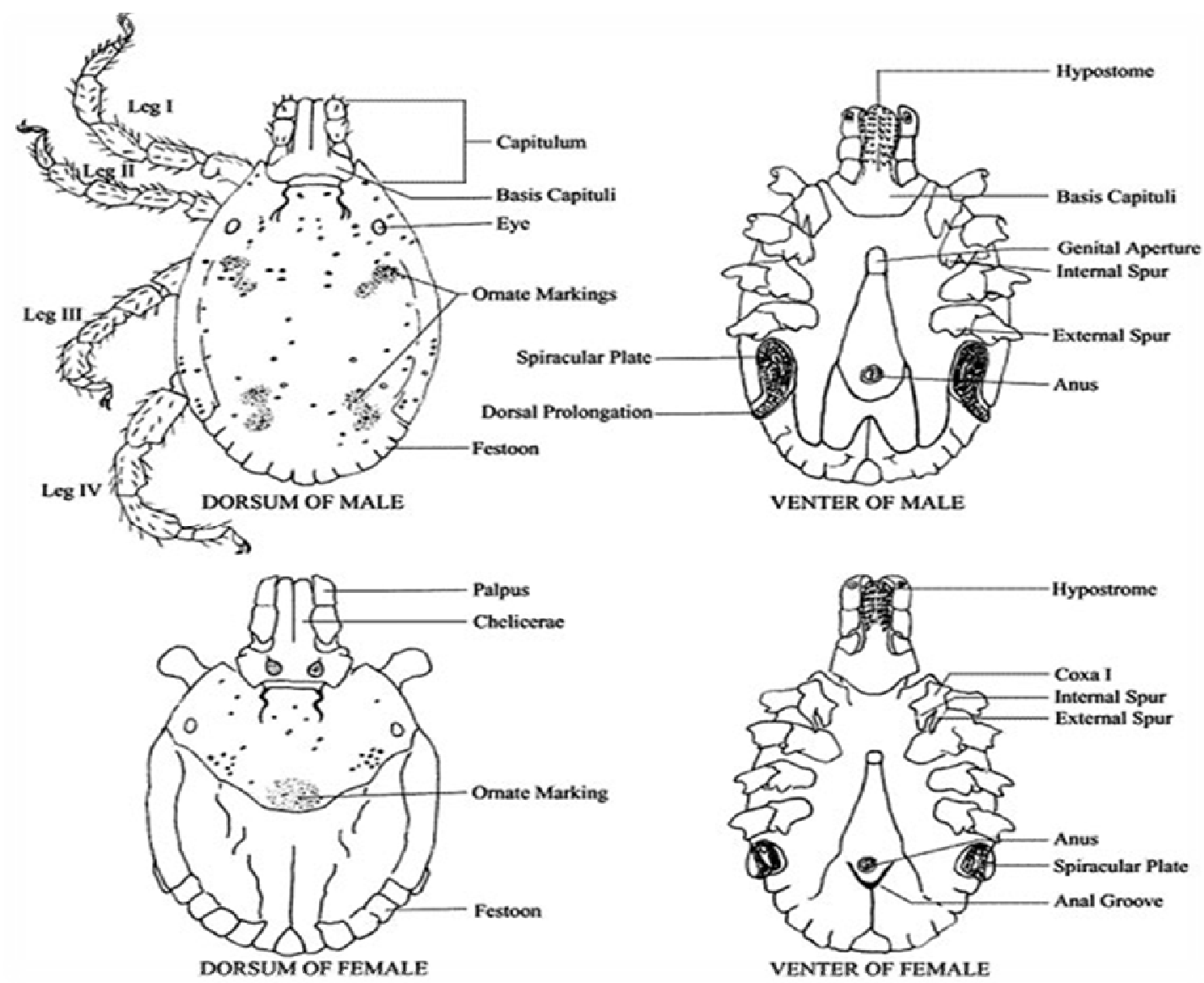

Figure7: Key physical features of male and female hard ticks on the top (dorsum) and bottom (venter) of their bodies.

Source: (Houseman, 2013)

\subsection{Epidemiology of ticks}

\subsubsection{Host relationship}

Some ticks live in open environments and crawl onto vegetation to wait for their hosts to pass by. This is a type of ambush and the behavior of waiting on vegetation of is called questing. Thus in genera such as Rhipicephalus, Haemaphysalis and Ixodes the larvae, nymphs and adults will quest on vegetation. The tick grabs onto the host using their front legs and crawl over the skin to find a suitable place to attach and feed. Adult tick of genera Ambylomma and Hyalomma are active hunters, they run across the ground after nearby hosts (Walker et al., 2003).

\subsubsection{Attachment site}

Tick attachment site specificity is one of the populations limiting system that operate through the restriction of tick species to certain parts of the host body. The ticks grab on to the hosts using their front legs and then crawl over the skin to find a suitable place to attach and feed. They seek out places on the hosts where they are protected and have favorable conditions for their development (Sathaporn et al., 2004).

Huruma et al. (2015) indicated that different ticks have different predilection sites on the host's body. The favorable predilection sites for B.decoloratus was the lateral and ventral side of the animal; A. variegatum, teat and scrotum; A. coherence udder and H.truncatum, scrotum and brisket and H.marginatum rufipes udder and scrotum, R.evertsi evertsi under tail and anus and R.preaxtatus anus and under tail (Huruma et al., 2015). Depending on the tick, site preference on the host depends on the accessibility for attachment, to get blood and protection to overcome the environment damage that inhibits its existence and grooming activity of the host. Tick location on the host is lined to the possibility of penetration by hypostome. Genera with short hypostome for example Rhipicephalus, Dermacentor and Haemaphysalis species usually attach to hairless area such as undertail and anovulval area (Huruma et al., 2015).

\subsection{Life cycle}

In the hard ticks mating takes place on the host, except with Ixodes where it may also occur when the ticks are 
still on the vegetation. Male ticks remain on the host and will attempt to mate with many females whilst they are feeding. They transfer a sac of sperm (spermatheca) to the female. The females mate only once, before they are ready to engorge fully with blood. When they finally engorge they detach from the host and have enough sperm stored to fertilize all their eggs. Female hard ticks lay many eggs $(2,000$ to 20,000$)$ in a single batch. Female argasid ticks lay repeated small batches of eggs. Eggs of all ticks are laid in the physical environment, never on the host (Charles and Robinson, 2006).

Members of the family Ixodidae undergo either one-host, two-host or three-host life cycles. During the one-host life cycle, ticks remain on the same host for the larval, nymphal and adult stages, only leaving the host prior to laying eggs. During the two-host life cycle, the tick molts from larva to nymph on the first host, but will leave the host between the nymphal and adult stages. The second host may be the same individual as the first host, the same species, or even a second species. Most ticks of public health importance undergo the three-host life cycle. The three hosts are not always the same species, but may be the same species, or even the same individual, depending on host availability for the tick. Argasid ticks have two or more nymphal stages, each requiring a blood meal from a host. Unlike the Ixodidae ticks, which stay attached to their hosts for up to several days while feeding, argasid ticks are adapted to feeding rapidly (about an hour) and then promptly leaving the host (Walker et al., 2003).

All feedings of ticks at each stage of the life cycle are parasitic. For feeding, they use a combination of cutting mouthparts for penetrating the skin and often an adhesive (cement) secreted from the saliva for attachment.The ticks feed on the blood and lymph released into this lesion. All ticks orient to potential hosts in response to products of respiration (Horak et al., 2002; Torres, 2008). The feeding of Ixodidae ticks is slow because the body wall needs to grow before it can expand to take a very large blood meal. Males of Ixodidae ticks feed but do not expand like the females. They feed enough for their reproductive organs to mature (Minjauw and McLeod, 2003).

\subsubsection{Life cycle one host ticks}

Eggs are laid on soil. Larvae hatch after several weeks of development and crawl onto vegetation to quest for a host. When they have completed feeding they remain attached to the host and moulting occurs there. The nymphs then feed on the same host and also remain attached. After another moult the adults hatch and then feed on the same host. The adults will change position on the same host for mating. Thus all three feedings of any individual tick occur on the same individual host. The life cycle of one-host ticks is usually rapid, for sub genus Rhipicephalus (Boophilus) it takes three weeks for the feedings on one host and two months for egg laying and larval development. The adult is considered the diagnostic stage, as identification to the species level is best achieved with adults. Few Ixodidae of public health importance follow this pattern; an example is Rhipicephalus (Boophilus) annulatus, which can serve as a vector for Babesiosis. Vertical transmission of Babesia via transovarial transmission has been demonstrated for some species of ticks (Walker et al., 2003 and Kirby, 2010).

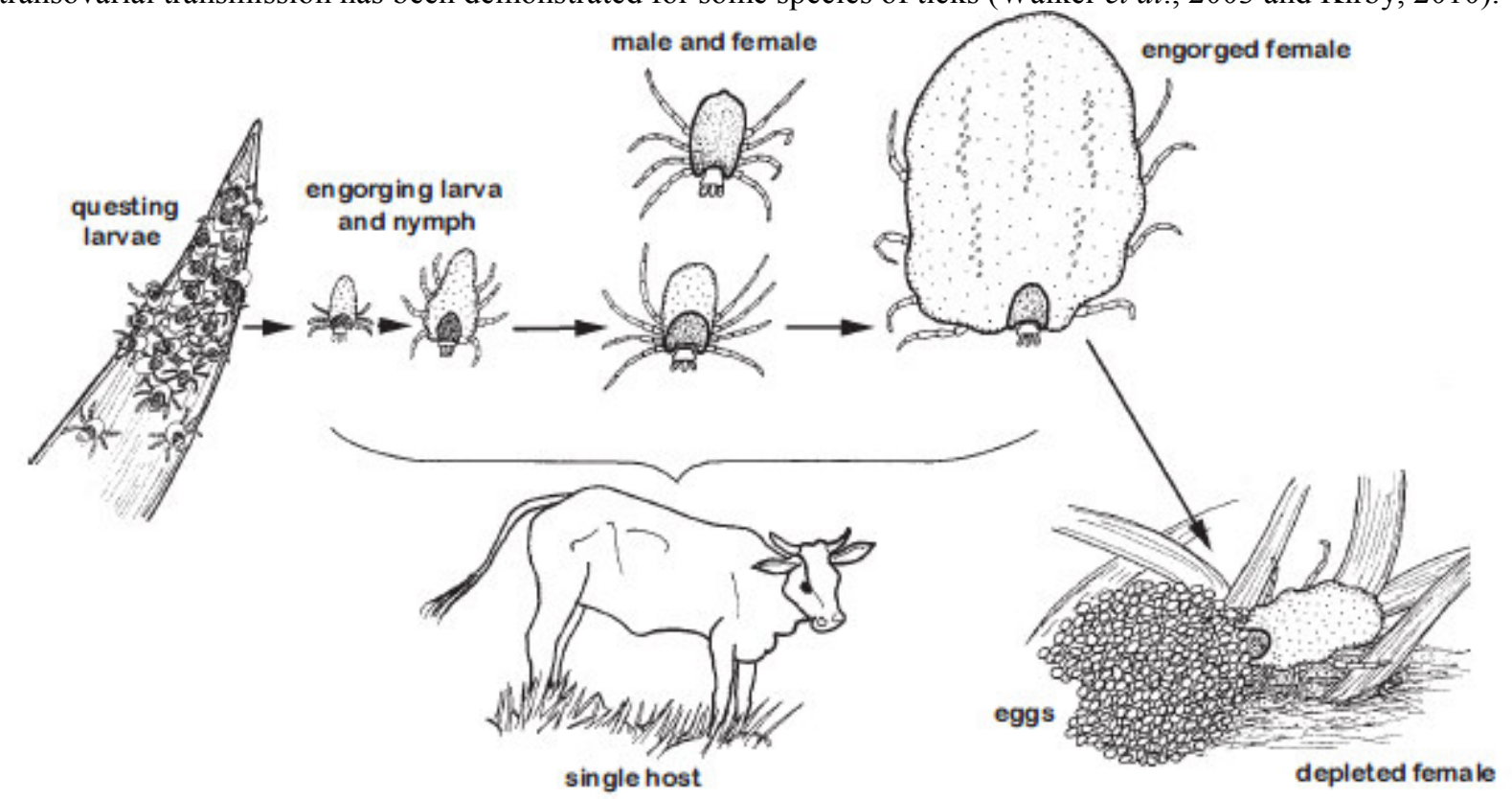

Figure 8: One-host tick life cycle

Source: (Walker et al., 2003).

2.4.2 Life cycle two host ticks

The two-host life cycle is similar to one-host life cycle but only the larvae and nymphs feed on the same 
individual host, and the adults will feed on another host. Hyalomma detritum detritum and Rhipicephalus evertsi evertsi have two-host life cycles. The adult is considered the diagnostic stage, as identification to the species level is best achieved with adults. An example of an Ixodidae tick of public health concern with this life cycle is Hyalomma marginatum, a vector of Crimean-Congo viral hemorrhagic fever. Two-host Ixodidae ticks have a life cycle that usually spans over two years. Gravid females drop off the second host after feeding to lay eggs. Adults feed on the second host during the summer and mate. In the fall, females drop off the second host to continue the cycle. Humans may serve as first or second hosts for ticks with this life cycle. Also, the second host does not necessarily have to be a separate species, or even a separate individual, as the first host (Walker et al., 2003; Kirby, 2010).

\subsubsection{Life cycle three host ticks}

This is the commonest type of life cycle. Larvae develop in the eggs until ready to hatch, usually in several weeks. Larvae feed once on a host, then detach from the host and hide in sites such as soil or vegetation. They moult to nymphs. Nymphs feed once and moult in the same way as larvae. From the nymphal moult either a female or male hatches. The female feeds once and lays one huge batch of eggs. The depleted female then dies. The male may take several small feeds, mate and then die. Ticks that have recently hatched from eggs or from moulting have soft bodies and are inactive for one to two weeks until the external body wall hardens. The life cycle of three host ticks is slow, from six months to several years. The adult is considered the diagnostic stage, as identification to the species level is best achieved with adults. Most ticks of public health importance follow this pattern, including members of the genera Ixodes (Lyme diseases or borreliosis, babesiosis, Amblyomma (tularemia, ehrlichiosis and Rocky Mountain spotted fever), Dermacentor (Rocky Mountain spotted fever, Colorado tick fever, tularemia, tick paralysis), and Rhipicephalus (Rocky Mountain spotted fever, boutonneuse fever). The three hosts do not necessarily have to be different species, or even different individuals. Also, humans may serve as first, second or third hosts (Walker et al., 2003; Kirby, 2010). Important Ixodidae ticks that feed on cattle according to the number of hosts required to complete life cycle are listed on table-1

Table 1: Important Ixodidae ticks according to the number of their hosts

\begin{tabular}{|c|c|c|c|}
\hline Tick genera & One host tick & Two host tick & Three host tick \\
\hline Rhi.(Boophilus) spp. & $\begin{array}{l}\text { Rhi.(B).decoloratus } \\
\text { Rhi.(B).annulatus } \\
\text { Rhi.(B).microplus }\end{array}$ & & \\
\hline Amblyomma spp. & & & All species of Amblyomma \\
\hline Hyalomma spp. & Hyalomma scupense & $\begin{array}{l}\text { H. m. turanicum, } \\
\text { H. d. dentritum }\end{array}$ & $\begin{array}{lr}\text { H.truncatum, } & \text { H.a.anatolicum, } \\
\text { H.dromedarii, } & \text { H.m.marginatum, } \\
\text { H.excavatum } & \\
\end{array}$ \\
\hline Rhipicephalus spps & & $\begin{array}{l}\text { R.e.evertsi } \\
\text { R. bursa }\end{array}$ & $\begin{array}{l}\text { Rh.simus, Rh.pravus, Rh.pulchelus, } \\
\text { Rh.Appendiculatus }\end{array}$ \\
\hline Haemaphysalis spp. & & & Hae.punctata \\
\hline Ixodes spp. & & & I.pilosus, I.ricinus \\
\hline Dermacentor spp. & D.albipictus & & Most species \\
\hline
\end{tabular}

Source: (Walker et al., 2003; Kirby, 2010)

\subsection{Cattle Resistance}

Resistance of cattle to tick infestation was reported to consist of innate and acquired components.

The defense mechanisms, including tick avoidance, grooming, skin characteristics and more specific immunological responses, are involved in reducing the number of ticks parasitizing cattle. Avoidance was attributed to the sighting of the ticks (Lora, 2001).

Spontaneous or acquired resistance may be following infestations, due to the development of cutaneous hypersensitivity. The mechanism responsible for acquired resistance to ticks has been suggested to be a mast cell-dependent eosinophil hypersensitivity (Minjauw and de Castro, 2000). Resistance can be passively transferred with viable lymph node cells but not with serum from resistant hosts. This passage method of tick resistance suggests a delayed hypersensitivity mechanism for the acquisition of resistance (Lodos et al., 2004).

The blood histamine level have been found to be elevated as a result of cutaneous basophiles or mast cells increase in resistant hosts, which degranulate in the region of ticks attachment to produce histamine. The histamine has shown to stimulate detachment of ticklarvae. But the infestation rate increases in normally resistant zebus either due to true inhibition by the allergic, or by reduced cutaneous pruritis that halts licking that enables to kill the larvae by resistant cattle (Torr et al., 2003 and Jonsson, 2006).

It has been recognized that various breeds of cattle differ in their response to tick infestations. Bos indicus pure breeds and crossbreeds were reported to be more innately resistant than Bos Taurus breeds (Minjauw and de Castro, 2000). According to the observation of authors, African cattle (Bos indicus) naturally 
self-groom and groom each other frequently and thoroughly. Significantly fewer ticks were found on those animals that were able to groom. Some breeds have the ability to reduce the number of ticks they carry and are considered resistant while others cannot control the number of ticks they carry and thus are referred to as sensitive breeds (Latif and Walker, 2004; Zahid et al., 2005).

A number of physiological and environmental factors can affect the level of host resistance to ticks or the expression of host resistance. Among which nutrition, sex, pregnancy, lactation, age, exposure to ticks, breed and tick density play key roles (FAO, 2004). Cattle lose resistance with time, and it seems that the older the animal, the lower the resistance. Pregnant cows were significantly more sensitive than non-pregnant female and carried a higher number of ticks mainly during the late stages of the pregnancy. The stress of lactation causes a marked decline in the resistance of exotic breeds; it also affect Zebu, but to a much smaller extent. Stable resistance is acquired after several months of exposure to the species of tick to which resistance is required (Minjauw and de Castro, 2000).

\subsection{Pathogenic Role of Ticks}

Direct effects of ticks on cattle are tick worry, blood loss, damage to hides and skins of animals and introduction of toxins (Marufu, 2008). The ecology and physiology of ticks have made them second most important vectors after mosquitoes. Ticks transmit a large variety of intercellular bacteria in the Rickettsia group like Rickettsia, Ehrlichia and Anaplasma. Similarly several piroplasm protozoa like T. annulata, T.parva and Babesiosis bigemmina are also transmitted specifically by ticks (Marquardat et al., 2005). Hard ticks (Acari: Ixodidae) are obligate hematophaguos ectoparasites and important vectors of viruses, bacteria and protozoa. They are considered second only to mosquitoes as the most medically important group of arthropods (Hubálek, 2010).

\subsubsection{Tick worry}

Tick worry is a generalized state of unease and irritability of cattle severely infested with ticks, often leading to serious loss of energy and weight. This negative effect on the growth of animals and their production is thought to be due to the effects of a toxin in the saliva of ticks (Marufu, 2008).

2.6.2 Anaemia

Anaemia is an inevitable consequence of heavy infestation by any blood-feeding parasite, and cattle deaths attributable to anaemia as a result of tick infestation are common (Jonsson, 2006).

Engorging Ixodidae females will increase their weight by 100-200 times but the actual amount of blood ingested is much greater than this, as blood meal is concentrated and fluid excreted in saliva. Estimates of the amount of blood removed vary according to the species under consideration (Marufu, 2008). The anaemia caused by heavy tick infestation results in loss of condition in cattle causing a reduction in meat production and milk yield (Marufu, 2008).

2.6.3 Wounds and myiasis

Ticks with longer mouthparts such as Amblyomma and Hyalomma cause more extensive damage than those with shorter mouthparts such as Rhipicephalus (Boophilus)and Rhipicephalus. The involvement of host reactions leading to tissue damage may be dependent upon recruitment of inflammatory responses characterized by dermal cell infiltrates which form the lesions (Mattioli et al., 2000). Tick wounds may become infested by screwworms or other agents of myiasis, and are also associated with the spread of bovine dermatophilosis caused by Dermatophilus congolensis (Kahn, 2006).

\subsubsection{Toxicoses}

Tick saliva contains toxins which have a specific pathogenic effect. The toxins affect not only the attachment site but also the entire organs of the host. Some ticks produce neurotropic toxins which induce tick paralysis that is characterized by an acute ascending flaccid motor paralysis (Kahn, 2006). Females of the species Hyalomma truncatum produce a dermotropic (epitheliotropic) toxin which causes sweating sickness in calves and some adult cattle (Kahn, 2006).

\subsection{Ticks Control Methods}

The aim of tick control campaign is not to control all ticks simultaneously, but a definite species because of its particular role (FAO, 2004). The successful implementation of rational and sustainable tick control programmes in grazing animals is dependent upon a sound knowledge of the ecology or epidemiology of the tick as it interacts with the host in specific climatic, management and production environments. In most situations, however, efficient and reliable methods for the control of cattle ticks and TBD are based on the use of a chemical treatment (acaricide application), often without a local understanding of appropriate ecology or epidemiology (FAO, 2004; Alanr, 2011).

The availability of each of these options, their advantages and disadvantages, and the cost benefit of each alternative strategy should be assessed before deciding on a control programme (Kirby, 2010). Ideally, strategies should target the parasitic and free-living phases of the life cycle and the role of the ticks in the 
transmission of TBDs should not be neglected (Solomon, 2001).

It is now generally understood that tick control should not only be based on acaricide use, despite the fact that this remains the most efficient and reliable single method. Complementary approaches have been developed and are being researched to enable integrated control strategies against the tick and its haemoparasites (Kirby, 2010; Alanr, 2011). The most common tick control methods used are briefly described as follows:

2.7.1 Ecological tick control

Ecological control method is used for habitat and host linked treatment. Tick control in the habitat and vegetation requires modification of the plant cover by removal of vegetation that shelters ticks (Kirby, 2010). Pasture management, including spelling and seasonal changes in cattle grazing areas in Australia and in Zambia respectively has been used as a tick control strategy and are believed to be responsible for a decrease its burden (Walker et al., 2003).

\subsubsection{Biological tick control}

A first attempt at tick biocontrol was made with the introduction of tick parasitic wasps from France to the USA and Russia. During the past decades, interest in developing antitick biocontrol agents such as birds, parasitoides, entomopathogenic nematodes, entomopathogenic fungi and bacteria have gained momentum (George et al., 2008). In biological tick control the activities of the hyperparasites chalcid flies Hunterellus are probably important in nature, but they are difficult to evaluate and it is still more difficult to manipulate or reproduce them for practical use. The biological agents, which potentially include predators like rodents, birds, ants, spiders, lizards and beetles as well as Prasitoids (destroy the host: the wasp lay the eggs in the engorged ticks and larvae eats the tick and emerges as adult to attack another tick) and parasites (Nematodes and fungus) are attack soil living stages of the ticks are effective and depending on the conditions, these predators can consume a large number of ticks (Latif and Walker, 2004 and Kirby, 2010). Yet, having such effective importance the development of a biological tick control methods has been neglected as compared to the control of plant pests or dipterous insects harmful to men and animals (Samish and Alekseev, 2001).

\subsubsection{Chemical tick control}

Acaricide treatments are commonly used in a suppressive approach, applying multiple treatments at regular intervals during the height of infestation. Suppressive treatments are the most effective in the short term; keeping animals almost tick free, thereby reducing the direct effect of the ticks and the risk of disease transmission. This procedure will, however, select heavily for acaricide resistance in the ticks (George et al., 2008).

An ideal acaricide would be cheap, easily applied, with a strong knock down effect and sufficient residual effect on female ticks to prevent egg lying and to protect cattle from reinfestation by larvae. It should not select for resistance through a prolonged, gradual decay on the animal (i.e. it should have a sharp cut off in efficacy with time). In addition, it should be non-toxic to livestock and humans and have no detectable residues in meat and milk. Unfortunately, such an ideal acaricide has not yet been produced. Generally, although the use of acaricides for the control of ticks has limitations and tick resistance to acaricides is an increasing problem and real economic threat to the livestock worldwide, most livestock holders depend completely on acaricides to control ticks, but do not have access to guidelines on how to make a profit from their tick control program or how to detect and resolve problems with resistance to acaricides (George et al., 2008).

\subsubsection{Genetic tick control}

The application of acaricides is the most common method used to control cattle ticks. However, the improper use of these chemicals compounds has been causing the development of tick resistance to various pesticides available in the market, reducing these products' useful lifetimes. Besides this, problems generated by the presence of chemical residues in meat, milk and the environment have prompted reflection on the need for better monitoring of their application (Castro-Janer et al., 2010). Therefore, the study of the genetic resistance to ticks among different breeds of cattle can contribute to the development of alternative control methods (Ibelli et al., 2011). It is widely known that Bos indicus cattle are more resistant to ectoparasites than are Bos taurus animals. There are great differences between these two breeds ofcattle in regard to theirsusceptibility to parasitism by cattle ticks (Bianchin et al., 2007). Studies are intensifying the crossing of these two groups, aiming to obtain animals that are more resistant to the conditions found in tropical countries and are also good meat producers (Graf et al., 2005). Tick resistance among cattle is influenced by a number of factors. The most important are increased levels of histamine at the early stages of the infestation, self-cleaning behavior (Ibelli et al., 2011), increased levels of eosinophils, basophils and mast cells, the presence of specific immunoglobulin patterns, and genes related to the expression of keratins and lipocalins (Kongsuwan et al., 2010).

\subsubsection{Tick vaccine}

A vaccine by contrast has the potential to be a non-contaminating, sustainable and cheap technology, potentially applicable to a wide variety of hosts. There are potential limitations as well, first and foremost whether vaccines can be produced which achieve the desired level of efficacy under field conditions (Willadsen, 2004).The Australian experience has shown that integrated control, involving a combination of strategies, is necessary because of the development of tick to acaricides. Integrated control has led to the widespread use of tick-resistant 
zebu cattle and vaccines against TBDs (Santana, 2000 and Silk, 2009). A tick-vaccine named "TICK GUARD" is on the market mainly in Australia and Latin America for the control of Rhipicephalus (Boophilus) microplus, which is prepared from antigens of tick gut multiplied with genetically engineered Escherichia coli. It acts essentially by damaging the tick gut thereby reducing tick fertility. The vaccine has been evaluated during the last 10 years and has demonstrated its safety as part of an integrated tick control programs. Unfortunately this vaccine is developed specifically for Rhi (Boophilus) microplus, which is the only major tick species of that country (Xu et al., 2005).

2.7.6 Ethno-veterinary in control of tick

Despite the major role in control of Acari, synthetic acaricides suffer from a large limitation. Because of the hard delayed degradation, their residues usually remain in agricultural environment where they adversely affect the life of living organisms in natural ecosystem. Likewise, they are able to induce the production of resistant strains of ticks (Habeeb, 2010). Ethno-veterinary medicine covers people's knowledge, skills, methods, practices and beliefs about the care of their animals (Moyo and Masika, 2008). In Kenya ethno-veterinary remedies are used among pastoral and farming communities in marginal areas (Njoroge and Bussmann, 2006). They are locally available and affordable to the farming communities (Moyo and Masika, 2008). Ethno-veterinary medicine provides valuable alternatives to and compliments the conventional acaricides especially where the later is unavailable, unaffordable or inappropriate. Some of the ethnoveterinary remedies have been documented and some have been validated for their acaricidal properties. For example, certain plants have been found to possess strong acaricidal and/ or tick repellent properties. These include: Nicotiana tabacum, Vernonia amygdalina, Tephrosiavogelii, Chrysanthemum cinerariaefolium (Hlatshwayo and Mbati, 2005). The ethno-veterinary remedies of tick control practiced in western Ethiopia have been examined by a survey of farmers, followed by in vitro and in vivo testing of treatments that appeared to have potential to control ticks (Regassa, 2000). Some plants with acaricidal properties have some side effects on animals for example application of latexes of Euphorbiaobovalifolia caused alopecia in areas of skin smeared with the latex (Regassa, 2000). In Ethiopia in north Gondar the use of some plants to control tick in animal using some plants such as Birbira (Milletia ferruginea), Zikita (Calpurnia auera), endod (Phytolacca dodecandra) and others was reported (Melaku, 2013). In Kenya, farmers are reported to mix $100 \mathrm{ml}$ of nicotine with about 1litre of used engine oil to make oil dressing to kill ticks (Forse, 1999). Uses of ethno-veterinary remedies probably reduce tick-burdens while maintaining endemic stability to tick-borne diseases. However little work has been done to document and validate these ethno-veterinary remedies in Ethiopia (Regassa, 2000).

\subsection{The distribution of ticks in Ethiopia}

In Ethiopia, studies on tick fauna have begun early in the $19^{\text {th }}$ century. Since then, different researchers from abroad and country determine the pattern of ticks and the TBDs; and ticks are common in all agro-ecological zones of the country (Pegram et al., 1981 and Morel, 1989). The main tick genera found in domestic animals of Ethiopia are Amblyomma, Hyalomma, Rhipicephalus, Haemaphysalis and Rhipicephalus (Boophilus) (Sileshi et al., 2007).

Among the genera Rhipicephalus, Rhipicephalus lunulatus species were observed in Central Ethiopia (Sileshi et al., 2001), and Rhipicephalus muhasmae in Borena (Regassa, 2001), in wetter western areas of the country (Pegram et al., 1981 and de Castro, 1994). Seyoum (2001) was recorded Rh. humoralis, Rh. cliffordi, Rh. compositus and Rh. distinctus in Wollo and Northeast areas. Rhipicephalus evertsi evertsi, "Red-legged tick" (Okello-Onen et al., 1999and Walker et al., 2003), is the most widespread species of Rhipicephalus (Sinshaw, 2000 and Solomon et al., 2004). Rhipicephalus pulchellus, "Zebra tick" (Okello-Onen et al., 1999and Walker et al., 2003), is distributed widely in the north eastern (Seyoum, 2001), eastern (Rahmeto et al., 2010) and southern rangel (Regassa, 2001; Solomon et al., 2004) part of the country. Rhipicephalus simus, "Glossy tick" (Walker et al., 2003), are found in northern (Sinshaw, 2000), eastern (Rahmeto et al., 2010), central (Sileshi et al., 2001).

Of the genus Amblyomma four species that commonly infest cattle includes Amblyomma variegatum, A. gemma, A. lepidum and A. cohaerens and are known to exist in Ethiopia (Morel, 1989; Walker et al., 2003; Sileshi et al., 2007; Abunna et al., 2012). Regassa (2001) in Borena zone showed that A. variegatum, A.gemma and A. lepidum distributed in wider area of southern Ethiopia. From the studies of Abebaw (2004) in Jimma A.variegatum and A. coherense are widely distributed in south western Ethiopia. Amblyomma variegatum and A. cohaerens are the two most prevalent Amblyomma speciesin Awassa areas in decreasing order (Berhane, 2004). In eastern Ethiopia, A.variegatum and A. gemma are the two most widely spread species (Bekele, 2002). Amblyomma gemma, "Gem-like bont tick" (Susan, 1998), is recorded in eastern and southern Ethiopia (Pegram et al., 1981 and de Castro, 1994). Ambylomma variegatum and Ambylomma coherence in was also recorded in Haramaya (Kassa and Ayalew, 2012; Bedasso et al., 2014). It is clearly associated with dry types of vegetation or semi-arid rangelands (Morel, 1989 and Pegram et al., 1981). Amblyomma lepidum, "East African bont tick"(Susan, 1998), is most commonly inhabits arid habitats and in open bushed shrub or wooded grassland and its distributions overlap with Ambylomma gemma and that of Ambylomma variegatum (Walker et al., 2003). 
Two species of Rhipicephalus (Boophilus) sub genus are known to exist in Ethiopia, which include Rhipicephalus (Boophilus) decoloratus and Rhipicephalus (Boophilus) annulatus. The study done by Regassa (2001) in Borena zone; Sileshi et al (2001) in central Ethiopia; Assefa (2004) in Asella; Berhane (2004) in Awassa; and Yitbarek (2004) in Jimma; Dessie (2005) in Wolayta; Tesema and Gashaw (2010) in Asella; Seyoum (2001) in Wollo and Asosa area(Fantahun and Mohammed, 2012) indicated the distribution of Rhipicephalus (Boophilus)decoloratus. Rhipicephalus (Boophilus) annulatus is known to present in Gambella region and recorded by Pegram et al (1981) and de Castro (1994).

In Ethiopia, about eight species of Hyalomma that affect cattle are identified, which includes Hyalomma marginatum rufipes, Hy. dromedarii, Hy. tuncatum, Hy.m. marginatum, Hy. impelatum, Hy. anatolicum excavatum, Hy.anatolicum anatolicum and Hy. albiparmatum (Pegram et al., 1981; Tiki and Addis; Sinshaw, 2000; Sileshi et al., 2001; Seyoum, 2001; Regassa, 2001; Bekele, 2002 ; Assefa, 2004; Ayalew et al., 2013 and Bedasso et al., 2014).

Haemaphysalis aciculifer, Haem.Parmata and Haem.leachispecies of the genus Haemaphysalis are known to infest Ethiopian cattle and distributed in all parts of the country(Pegram et al., 1981; Seyoum, 2001; Sileshi et al., 2001 and Walker et al., 2003).

\subsection{Tick borne diseases and status of tick borne haemoparasitic diseases in Ethiopia}

\subsubsection{Tick Borne Diseases}

The term vector-borne disease refers to any of a broad array of infectious diseases caused by pathogens that are transmitted by arthropods or other biologic intermediaries. Although transmission usually occurs on blood feeding by an infected insect or acarine parasite, infection can also result when a vertebrate host ingests a vector or on contamination of a wound by infectious organisms in the feces of the arthropod intermediary. Regardless of the means of transmission, the vector, a critical component in disease transmission, engages in a lifestyle that is at least partially parasitic and that somehow contributes to its ability to both acquire and serve as a source of infection to animals (Bowman, 2009).

Ticks are effective disease vectors, second only to mosquitoes in transmitting infectious disease (Le Bars, 2009). Some of the most important tick-borne diseases are East Coast Fever, Redwater, anaplasmosis and heartwater. Many other fatal and benign babesiosis, theileriosis and anaplasmosis are also transmitted by various tick species (Jongejan and Uilenberg, 2004). These diseases generally affect the blood and/or lymphatic system and cause fever, anaemia, jaundice, anorexia, weight loss, milk drop, malaise, swelling of lymph node, dyspnoea, diarrhoea, nervous disorders and even death. Major cattle tick-borne diseases in Ethiopia are anaplasmosis, babesiosis, theileriosis (Mekonnen et al., 1992) and Dermatophilosis (Mekonnen, 1996). Besides to disease transmission ticks inflict a huge economic loss. TTBDs around the globe have been estimated at US\$13.9 to US\$ 18.7 billion annually leaving world's 80\% cattle at risk (Ghosh et al., 2007). Bekele (2002) estimated an annual loss of US\$ 500,000 from hide and skin downgrading from ticks, and approximately $65.5 \%$ of major defects of hides in eastern Ethiopia are from ticks. Furthermore, the costs associated with maintaining chemical control of ticks in tropical and subtropical regions of the world have been estimated at US\$ 25.00 per head of cattle per year (Pegram, 2001)

\subsubsection{Status of tick borne haemoparasitic diseases in Ethiopia}

Similar to other countries, there are a considerable number of economically important livestock diseases occurring in Ethiopia. Among others, tick borne haemoparasitic diseases are of the major constraints to the livestock industry of the country. Sileshi (1994) indicated the existence of Anaplasmosis, Babesiosis, Cowdriosis and Theileriosis (T. mutans), but their significance in terms of mortality and productive losses and the degree of enzootic stability are not yet very well known. Only Feseha (1983) reported a conservative estimate of birr 1 million loss annually through rejection or downgrading of hide and skin. Moreover, light to severe inflammatory reaction sometimes leading to surgical removal of teats are damages caused by ticks

There are no clinical or serological reports of the presence of either T.annulata or T. parva in Ethiopia. But, there is relatively uncontrolled movement of livestock from Sudan and Kenya, where these diseases and their vectors are found (Sileshi, 1994). In previous studies, conducted by Mekonin et al., 1992; Becerra et al., 1983; Radeley, 1980; B. bovis, T. orientalis and T. velifera were reported from Gambella region, western Ethiopia. 
Table: 2 Existing TB haemoparasitic diseases in four regions of Ethiopia

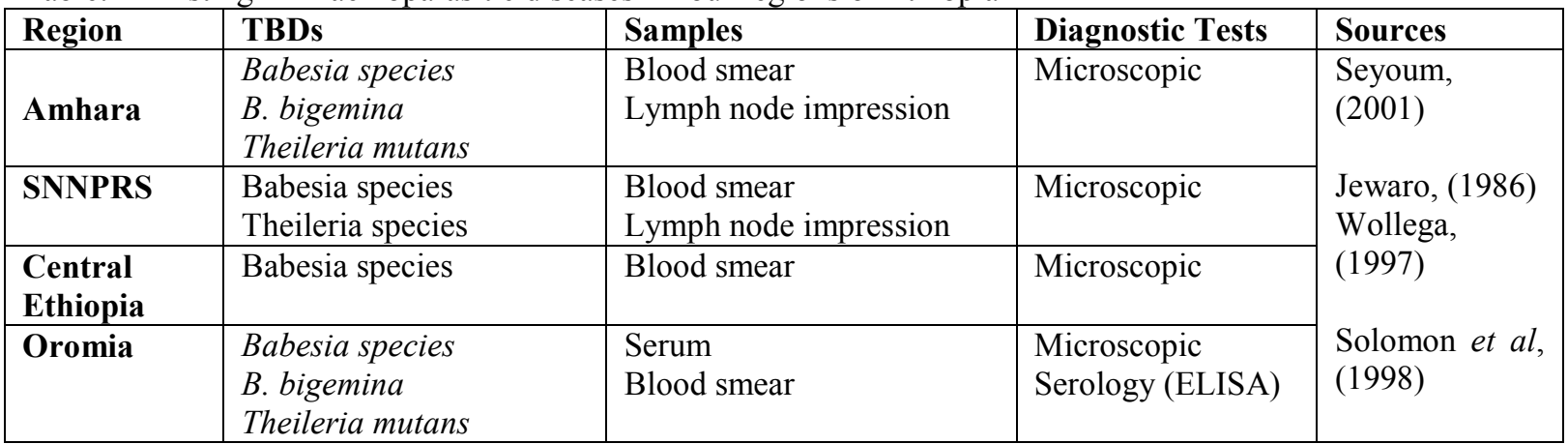

\section{CONCLUSIONS AND RECOMMENDATIONS}

Ticks are obligate blood feeding ectoparasites of vertebrates and induce huge production loss in livestock industry and creating serious public health problems in the world. The main tick genera found in Ethiopia are Amblyomma, Boophilus, Haemaphysalis, Hyalomma and Rhipicephalus. Tick-borne diseases of cattle such as anaplasmosis, babesiosis, cowdriosis and theileriosis (T. mutans) are present in Ethiopia. Heavy infestations by different tick species suppress the immunity of cattle and also damage teats and reduce productivity of animals and there are direct effects associated with tick infestation that leads to tick worry, anorexia and anemia. These all are the impacts of tick infestation so, to minimize tick impact appropriate and timely strategic control measures are crucial. The conventional method of controlling tick infestations in Ethiopia is application of acaricide, either by hand spraying, by hand dressing. The availability of vaccine is very small. The ability to induce an effective, sustained immunological response is crucial but needs improvement. Problems of acaricide resistance, chemical residues in food and the environment and the unsuitability of tick resistant cattle for all production systems make the current situation unsatisfactory and require the development of absolute control through effective vaccine. Therefore, in line with the above conclusions; the following recommendations were forwarded:

$>$ The government should monitor the use of potentially dangerous chemicals and conserve foreign exchange.

$>$ Intensive acaricide application to control ticks has a number of limitations, Therefore, immunization together with strategic tick control are recommended for exotic and crossbred cattle

$>$ Research should be conducted on tick species and their epidemiology for the continuous understanding of improved control strategies

$>$ Awareness should be given to animal breeder on problem of tick and TBD and different control method.

\section{ACKNOWLEDGEMENTS}

Above all, I would like to praise my Almighty God, Allah, for supporting me health, wisdom and strength in my work and for his perfect protection and guidance of my life. I would like to express my sincere thanks and best regards to my beloved and respected family for their invaluable help and encouragement during my journey for their moral and financial support throughout my entire academic career Finally I would like to thanks all my friends those who helped me for my successfulness.

\section{REFERENCE}

Abunna, F., Tura, J., Regassa, A. (2012): Status of Tick Infestation in Small Ruminants of Bedelle District, Oromia Region, Ethiop. Glob. Vet., 8 (5): 459-462.

Alanr, W. (2011): Eradication and control of livestock ticks: biological, economic and social perspectives. Royal (Dick) School of Veterinary Studies, University of Edinburgh, Summerhall Place, Edinburgh EH9 1QH, UK, Pp: 236-253.

Assefa, B. (2004): A survey of ticks and tick-borne blood protista in cattle at Asela, Arsi Zone. DVM thesis, Addis Ababa University, Faculty of Veterinary Medicine, Debre Zeit. Pp: 25-36

Barker, S. C. and Murrell, A. (2004): Systematic and evaluation of ticks with a list of valid genus and species names. J.Parasitol., 129 (7): 15-36.

Bedasso,M.,Abebe, B. and Degefu, H. (2014): Species composition, prevalence and seasonal variations of Ixodidae cattle ticks in and around Haramaya town, Ethiopia Full Length Research Paper 6(5), Pp: 131-137.

Bekele, T. (2002): Studies on seasonal dynamics of ticks of Ogaden cattle and individual variation in resistance to ticks in Eastern Ethiopia. J. Vet. Med. 49: 285-288.

Berhane, M. (2004): Distribution of livestock tick species in Awassa area. DVM thesis, AAU, FVM, Debre-Zeit, 
Pp: 1-16.

Bianchin, I., Catto, J.B., Kichel, A.N., Torres, R.A.A., Honer, M.R. (2007): The effect of the control of endoand ectoparasites on weight gains in crossbred cattle (Bos taurus taurus $\times$ Bos taurus indicus) in the central region of Brazil. Trop. Anim. Health. Prod. 39, 287-296.

Bowman, D.D. (2009): Georgis Parasitology for veterinarian $9^{\text {th }}$ editon. Newyork. Pp: 1-465.

Castro-Janer, E., Martins, J.R., Mendes, M.C., Namindome, A., Klafke, G.M., Schumaker, T.T.S. (2010): Diagnoses of fipronil resistance in Brazilian cattle ticks Rhipicephalus (Boophilus) microplus using in vitro larval bioassays. Vet. Parasitol.173, 300-306.

Charles, M. H. and Robinson. E. D. (2006): Diagnostic Parasitology for Veterinary technicians $3^{\text {rd }}$ edition. Pp: 192-195

CSA. (2013): Federal Democratic Republic of Ethiopia, Central Statistical Authority, Agricultural sample survey (2012/2013), Report on livestock and livestock characteristics (Privet and Peasant Holdings), Addis Ababa. Pp: 9-20.

de Castro, J. J. (1994): A survey of the tick species in western Ethiopia including the previous findings and recommendation, for further tick survey in Ethiopia. Technical report AG: DP/ETH/83/023, FAO. Rome, Pp: 1-83.

de Castro, J. J. (1997): Sustainable tick and tick-borne disease control in livestock improvement in developing countries. Vet. Parasitol.,71, 77-97.

Dessie, S. (2005): Cattle Tick Dynamics in Different Agro-Ecological Zones of Wolayta, Southern Ethiopia. Master thesis, Addis Ababa University, Faculty of Veterinary Medicine, Debre Zeit, Ethiopia. Pp: 1883.

Fantahun, B. and Mohamed, A. (2012): Survey on the Distribution of Tick Species in and Around Assosa Town, Ethiopia. Research Journal of Veterinary Sciences, 5:32-41.

FAO. (2004): "Acaricide resistance: diagnosis, management and prevention," in Guidelines Resistance Management and Integrated Parasite Control in Ruminants, Animal Production and Health Division, Agriculture Department, Food and Agriculture Organization of the United Nations, Rome, Italy, Pp: $25-77$.

Forse, B. (1999): Where there is no vet. Macmillan Press Ltd., London and Oxford, UK. Pp: 435-442.

George, J. E., Pound, J. M. and Davey, R. B. (2008): Acaricides for controlling ticks on cattle and the problem of acaricide resistance. In Ticks: Biology, Disease and Contro. Cambridge University Press, UK, Pp: $408-423$.

Ghosh, S., Azhahianambia, P., Yadav, M.P. (2007): Upcoming and future strategies of tick control: a review. $J$. Vect. Born. Dis. 44: 79-89.

Graf, J. F., Gogolewski, R., Leach-Bing, N., Sabatini, G. A., Molento, M. B., Bordin, E.L., Arantes, G.J. (2005): Tick control: an industry point of view. Parasitology, 129, S427-S442.

Habeeb, S. M. (2010): Ethno-veterinary and medical knowledge of crude plant extract and its method of application (traditional and modern) for tick control. Department of parasitology and animal diseases, Giza, Egypt.World applied sciences journal, 11(9), 1047-1054.

Hlatshwayo, M. and Mbati, P. A. (2005): A Survey of tick control methods used by resource poor farmers in the Qwa-Qwa area of the eastern Free State Province, South Africa. Ondersteport Journal of Veterinary Research, 72(3): 245-249.

Horak, I., Camicas, J. and Keirans, J. (2002): The Argasidae, Ixodidae and Nuttalliellidae (Acari: Ixodidae): A world list of valid tick names. Exper.Applied Acarology,28: 27-54.

Houseman, R. M. (2013): Guide to Ticks and Tick-Borne Diseases University of Missouri Extension, IPM1032.

Hubálek, Z. (2010): Biogeography of Tick-Borne Bhanja Virus (Bunyaviridae) in Europe. Interdisciplinary Perspectives on Infectious Diseases.doi: 10.1155/2009/372691.

Huruma G, Abdurhaman M, Gebre S, Deresa B (2015). Identification of tick species and their prevalence in and around Sebeta town, Ethiopia.J. Parasitol.Vect. Biol. 7(1):1-8.

Ibelli, A. M. G., Ribeirob, A. R. B., Giglioti, R., Regitanod, L. C. A., Alencard, M. M., Chagasd A. C. S., Pac, A. L., Oliveirac, H. N., Duartee J. M. S. and Oliveirad, M. C. S. (2011): Resistance of cattle of various genetic groups to the tick Rhi.(Boophilus) microplus and the relationship with coat traits. Vet. Parasitol. doi:10.1016/j.vetpar.2011.11.019.

Jewaro, A. (1986). A survey of tick and tick born disease in Gamo Gofa administrative region DVM thesis. Faculty of Veterinary Medicine, Addis Ababa University, Debre zeit, Ethiopia.

Jongejan, F. and Uilenberg, G. (2004): The Global importance of ticks. Parasitology, 29 (Supp): 513-514.

Jonsson, N. N. (2006): The productivity effects of cattle tick infestation on cattle, with particular reference to Bos indicus cattle and their crosses. Vet. Parasitol, 137 (2): 1-10.

Kahn, C. M. (2006: The Merck Veterinary Manual, $9^{\text {th }}$ Edition, Merck and Co. Inc, Whitehouse Station, USA.

Kassa, B. (2005): Standard Veterinary Laboratory Diagnostic Manual. Veterinary Diagnostic Laboratory, 
College of Veterinary Medicine at the University of Illinois at Urbana, Urbana, IL. USA.

Kassa, S.A. and AyalewA. (2012): Identification of Ixodideticks of cattle in and around Haramaya district, Eastern Ethiopia.Haramaya University College of Veterinary Medicine.Scientific Journal of Crop Science.1(1) 32-38.

Kaufman, P. E., Koehler, P. G. and Butler, J. F. (2006): External Parasites on Beef Cattle.Entomology and Nematology Department, Florida Cooperative Extension Service, Institute ofFood and Agricultural Sciences, University of Florida. Pp: 420-490.

Kirby, C. (2010): Tick Management Hand book. Biological tick Control, $2^{\text {nd }}$ Edit. The Connecticut Agricultural Experimentation Station, New Haven, Pp: 70-71.

Kongsuwan, K., Josh, P., Colgrave, M.L., Bagnall, N.H., Gough, J., Burns, B., Pearson, R. (2010): Activation of several key components of the epidermal differentiation pathway in cattle following infestation with the cattle tick Rhipicephalus (Boophilus) microplus. Int. J.Parasitol. 40, 499-507.

Latif, A. A. and Walker, A. R. (2004): An introduction to the biology and control of ticks in Africa. ICTTD-2 project, Pp: 1-29.

Le Bars, C. (2009): Tick-borne disease management. Veterinary Times, $18^{\text {th }}$ May.

Lodos, J., Boue, O. and Fuente, J. (2000): Model to simulate the effect of vaccination against Boophilus ticks on cattle. Vet. Parasitol.87 (4), 315-326.

Lora, R. B. (2001): Veterinary Parasitology. The Practical Veterinaria, Arthropods. Butterworth-Heinemann, A member of the Reed Elsevier group, Library of Congress Cataloging, United State of America, Pp: 1621.

Marufu, M. C. (2008): Prevalence of Ticks and Tick-borne Diseases in Cattle on CommunalRangelands in the Highland Areas of the Eastern Cape Province, South Africa. Master of Science in Agriculture (Animal Science) in the Department of Livestock and Pasture Science Faculty of Science and Agriculture. Pp: $1-134$.

Mattioli, R. C., Pandey, V. S., Murray, M. and Fitzpatrick, J. L. (2000): Review: Immunogenetic influences on tick resistance in African cattle with particular reference to trypanotolerant N'Dama (Bos taurus) and trypanosusceptible Gobra zebu (Bos indicus) cattle. Acta Tropica, 75(3): 263-277.

Mekonnen, S. (1996): Epidemiology of ticks and tick-borne diseases in Ethiopia: Future research needs and priorities. In: Irvin A.D., McDermott J.J. and Perry B.D. (eds), Epidemiology of Ticks and Tick-borne Diseases in Eastern, Central and Southern Africa. Proceedings of a Workshop Held in Harare, 12-13 March 1996. ILRI (International Livestock Research Institute), Nairobi, Kenya. Pp: 174

Mekonnen, S., de Castro, J., Gebre, S., Hussein, I., Regassa, A. (1992): Ticks, tick-borne diseases and their control in Western Ethiopia. Int. J. Trop. Ins. Sci.13: 661-664.

Mekonnen, S., Hussen I. and Bedane, B. (2001): The distribution of ixodidae ticks (Acari: Ixodidae) in central Ethiopia. Onderstepoort J. Vet. Res., 68: 243-251.

Melaku, A. (2013): Ethnoveterinary practices and Potential Herbal Materials for the Treatment of Ticks in North Gondar, Ethiopia. J. Intercult. Ethnopharmacol.2(2):85-90 available at www.scopemed.org accessed $10 / 23 / 2015$.

Mesfin, T. and Lemma, M. (2001): The role of traditional veterinary herbal medicine and itsconstraints in the animal health care system in Ethiopia. In: Conservation and Sustainable Use of Medicinal Plants in Ethiopia. Medhin, Z. and Abebe, D. (Eds): Institute of Biodiversity conservation and Research. Addis Ababa, Ethiopia. $\mathrm{P}_{\mathrm{P} .} 22$ - 28.

Minjauw, B. and de Castro, J. J. (2000): Host resistance to ticks and tick-borne diseases: Its role in integrated control. Breeding for Diseases Resistance in Farm Animals. CAB International, Pp: 153-169.

Minjauw, B. and McLeod, A. (2003): Tick-borne diseases and poverty. The impact of ticks and tick-borne diseases on the livelihood of small-scale and marginal livestock owners in India and eastern and southern Africa.Research report, DFID Animal Health Programme, center for Tropical Veterinary Medicine, University of Edinburgh, UK. Pp: 1-116.

MoARD (2008): The effect of skin and hide quality on domestic and export market and evaluation of the campaign against ectoparasites of sheep and goat in Amhara, Tigray and Afar region, official report to Region and other sectors, Addis Ababa, Ethiopia.

Morel, P.C. (1989: Manual Tropical Veterinary Parasitological. CAB International, UK, Pp: 299-460.

Moyo, B. and Masika, P.J. (2008): Tick control methods used by resource-limited farmers and the effect of ticks in cattle in rural areas of the Eastern Cape Province, South Africa. Tropical Animal Health and Production, 41(4): 517-523.

Mtshali, M. S., de Waal, D. T. and Mbati, P.A. (2004): A sero-epidemiological survey of blood parasites in cattle in the north-eastern Free State, South Africa. Onderstepoort Journal of Veterinary Research, 71:67-75.

Njoroge, G. N., and Bussmann, R. W. (2006): Herbal usage and informant consensus in ethnoveterinary management of cattle diseases among the kikuyus (Central Kenya). Journal of ethnopharmacology, 
108: $332-339$

Okello-Onen, O. J., Tukahirwa, E. M., Paerry, B. O., Rowlands, G. J., Nagda, S. M., Musis, G., Bode, E., Heinonen, R., Mwayi, W. and Opuda-Asodo, J. (1999): Population dynamics of ticks on indigenous cattle in pastoral dry to semi arid range land zone of Uganda. Experimental and applied acarology, 23: 79-88.

Olwoch, J. M. Revers, B. and Van Jaarsveld, A. S. (2009): Host parasite distribution patterns under simulated climate: International Journal of Current Research, Vol. 4, Issue, 05, Pp: 073-076.

Pegram, R. G. (2001): Getting a handle on tick control: A modern approach may be needed. Vet. J., 161: 227228.

Pegram, R. G., and Chizyuka, H.G. B. (1990): The impact of natural infestation ofticks in Zambia on the productivityof cattle and implications of tick control strategies in Africa. Parasitologia, 32:165-176.

Pegram, R. G., Hoogstraal, H. and Wassef, H. P. (1981): Ticks (Acari: Ixodidae) of Ethiopia. Distribution, Ecology and Host relationship of tick species infecting livestock.Bulletin of Entomology Research, 71 (9): 339-359.

Radostits, M. O., Gay, C. C., Blood D. C. and Hinchcliff, K. W. (2000): Veterinary Medicine: a text book of the diseases of cattle, sheep, pigs, goats and horses. Saunders, London, Pp: 1401-1405.

Radostits, O. M., Gray, C. C., Hinchcliff, K. W. and Constable, P. D. (2006): Veterinary Medicine. A text book of the Disease of Cattle, horses, sheep, pigs and goats; 10th Edition Oxford, New York, Pp: 1508-1520.

Rahmeto, A., Thedrous, F., Mesele, A. and Jemere, B. (2010): Survey of ticks infesting cattle in two districts of Somali Regional State, Ethiopia. Veterinary World, 3 (12):539-543.

Rajput, Z. I., Hu, S., Chen, W., Arijo, A. G. and Xiao, C. (2006); Review: Importance of ticks andtheir chemical and immunological control in livestock. Journal of Zhejiang University Science B, 7(11): 912-921.

Regassa, A. (2000): The use of herbal preparations for tick control in Western Ethiopia. Journal of the South African Veterinary Association, 71(4): 240-243.

Regassa, A. (2001): Tick infestation of Borana cattle in the Borana Province of Ethiopia. Onderstepoort Journal of Veterinary Research, 68 (8): 41- 45.

Rodríguez-Vivas, R. I., Mata, M. Y., Pérez, G. E. and Wagner, W. (2004): The effect of management factors on the seroprevalence of Anaplasma marginale in Bos indicus cattle in the Mexican tropics. Tropical Animal Health Production, 36 (4): 135-143.

Samish, M. and Alekseev, E. (2001): Arthropods as predators of ticks. J. Med. Enthomol., 38 (21):1-11.

Santana, V. L. A. (2000): Situation of chemical control of Boophilus microplus the sub-regions in the area of forest and wasteland in the state of Pernambuco, based on in vitro efficacy of acaricides in engorged females. Dissertation in Veterinary Science, Federal Rural University of Pernambuco, Recife, Pernambuco, Brazil.

Sathaporn, J. A, Weeraphol, J. A., Omar, O., Barriga, B. and Roger, W. (2004): Reduced Incidence of Babesia bigemina Infection in Cattle Immunized against the Cattle Tick, Boophilus microplus. Departement of Parasitology.FVM, Kasetsart University, Bangkok, Thailand. Pp: 36-47.

Seyoum, Z. (2001): Study of ticks and tick-borne diseases on cattle at Girana valley in the North Wollo Zone. Proceeding of the Ethiopian Veterinary Association, Vol.15.

Sileshi, M., A. Kgasi, W. Mureithi, Getachew, Z., Tilahun, T., Solomon, G., Yilma, J. and N. R. Bryson. (2004): In Vivo and In Vitro Evaluation Of The Efficacy Of Cypermethin High- Cis (Ecotomin®) Against Cattle Ticks In Ethiopia. Ethiop. Vet. J., 8 (1): 29-38

Sileshi, M., Hussein, I. and Bedane, B. (2001): The distribution of Ixodidae ticks (Acari: Ixodidae) in central Ethiopia. Onderstepoort J. Vet. Res., 68 (4): 243-251.

Sileshi, M., Pegram, L. G., Solomon, G., Abebe, M., Yilma, J. and Sileshi, Z. (2007): A synthesis review of Ixodid (Acari: Ixodidae) and Argasid (Acari: Argasidae) ticks in Ethiopia and their possible roles in disease transmission. Ethiop. Vet. J. 11(2): 1-24.

Silk, P. (2009): Occurrence of tick borne haemoparasites Kwazulu-Natal and Eastern Cape Provines, South Africa. MSc thesis in Veterinary Tropical Diseases, F.V.Science, University of Pretoria, South Africa. Pp: 6-7.

Sinshaw, S. (2000): Distribution of ticks and tick-borne diseases at Metekel Ranch. Ethiopian Veterinary Journal 1 (4): 40-59.

Solomon, G., M. Night and B, Kassa. (2001): Seasonal variation of tick on calves at Sebeta in Weastern Shewa Zone. Ethiopian Vet. J., 7: 17-30.

Solomon, G., Sileshi, M., Kaaya, G. P., Tilahun, T. and Yilma, J. (2004): Prevalence of Ixodid ticks and Trypanosomosis in camels in southern Ethiopia. Ethio. Vet. J., 8 (2): 23.

Stachurski, F., Musonge, E. N., Achu-Kwi, M. D. and Saliki, J.T. (1993): Impact of naturalinfestation of Amblyomma variegatum on the liveweight gain of male Gudali cattle in Adamawa(Cameroon). Veterinary Parasitology, 49: 299-311. 
Susan, E. Aiello. (1998): The Merck Veterinary Manual, $8^{\text {th }}$ edit, Merck and Co. Inc., USA, 67.

Tesema, T.and Gashaw A. (2010): Prevalence of ticks on local and crossbred cattle in and around Asella town, southeast Ethiopia. Ethiop. Vet. J., 14(2), 79-89.

Tiki, B. and Addis, M. (2011): Distribution of Ixodidae Ticks on Cattle in and Around Holeta Town, Ethiopia Global Veterinaria,7 (6): 527-53.

Torr, S., Eisler, M., Coleman, P., Morton, J. and Machila, N. (2003): Integrated control of ticks and tsetse. A report for the DFID advisory and support service contract, project ZV Pp: 1-135.

Torres, D. F. (2008): The brown dog tick Rhipicephalus sanguinus (Acari: Ixodidae): From taxonomy to control. Veterinary Parasitology, 152 (9):173-185.

Walker, A. R., Bouattour, A., Camicas, J. L., Estrada-Pena, A., Horak, I. G., Latif, A. A., Pegram, R. G. and Preston, P. M. (2003): Ticks of domestic animals in Africa: a guide to identification of species, Bioscience report. Pp: 1-221.

Wall, R., and Shearer, D. (2001): Veterinary ectoparasite: Biology, Pathology and control. $2^{\text {nd }}$ edition. Blackwell science, United Kingdom, Pp: 55-60.

Wasihun, P and Doda, D. (2013): Study on prevalence and identification of ticks in Humbo district, Southern Nations, Nationalities, and People's Region (SNNPR), Ethiopia Journal of Veterinary Medicine and Animal Health Vol. 5(3), Pp:73-80.

Willadsen, P. (2004): Anti-tick vaccines. Veterinary Parasitology.Cambridge University Press, UK. 129, S367S387.

Wollega, D. (1997). Survey of ticks and tick born disease in eight domestic animals in and round Deberzeit. Addis Ababa University, Facility of Veterinary Medicine Deberzeit. DVM Thesis, Eastern Showa, 1-79.

$\mathrm{Xu}$, Y., Bruno, J. F. and Luft, B. J. (2005): Identification of Novel ticks salivary gland proteins for vaccine development. Biochem B. Res Commun. Department of Medicine, Staet University of New York at Stony Brook, Stony Brook, NY 11794, USA, 326 (4): 4-901.

Yitbarek, G. (2004): Tick species infesting live stock in Jimma area, Southwest Ethiopia. DVM Thesis, Faculty of Veterinary Medicine, Addis Ababa University, Deberezeit, Ethiopia.

Zahid, I. A., Latif, M. and Baloch, K. (2005): Incidence and Treatment of Theileriosis and Babesiosis. Research Institute for Physiology of Animal Reproduction Bhunikey (Pattoki), District Kasur, Pakistan.Pakistan, Vet. J., 25 (3):137-141. 